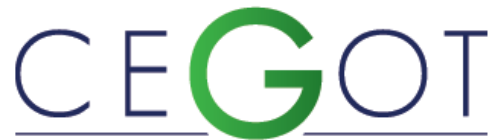

Centro de Estudos de Geografia e Ordenamento do Território
ALMEIDA, JUSCINALDO

Universidade Estadual do Maranhão / Programa de Pós-

Graduação em Geografia, Natureza e Dinâmica do Espaço

Cidade Universitária Paulo VI - Caixa Postal 09, 65055-310 São Luís, Brasil

juscinaldogoes@hotmail.com

JUNIOR, JOSÉ

Universidade Estadual do Maranhão / Programa de Pós-

Graduação em Geografia, Natureza e Dinâmica do Espaço

65055-310, Caixa Postal 09, São Luís, Brasil

sampaio.uema@gmail.com

\title{
A luta pela terra frente à dinâmica territorial do agronegócio da soja no Maranhão: o caso da Microrregião de Chapadinha (1990 - 2015)
}

The struggle for land in the territorial dynamics of soybean agribusiness in Maranhão: the case of the Microregion of Chapadinha (1990 - 2015)

Referência: Almeida, Juscinaldo; Junior, José (2019). A luta pela terra frente à dinâmica territorial do agronegócio da soja no Maranhão: o caso da Microrregião de Chapadinha (1990 - 2015). Revista de Geografia e Ordenamento do Território (GOT), n. ${ }^{\circ} 16$ (março). Centro de Estudos de Geografia e Ordenamento do Território, p. 251-274, dx.doi.org/10.17127/got/2019.16.011

\section{RESUMO}

O presente artigo analisa o processo de expansão da produção de soja no Maranhão, com destaque especial para a microrregião de Chapadinha, inserida na denominada mesorregião Leste Maranhense. Analisa-se também a luta pela terra daí decorrente, envolvendo camponeses e produtores sulistas denominados gaúchos.

Palavras-chave: Luta pela terra. Expansão da Soja. Microrregião Chapadinha. Maranhão.

\section{ABSTRACT}

This article analyzes the process of expansion of soybean production in Maranhão, with special emphasis on the Chapadinha microregion, which is part of the Maranhense East mesoregion. We also analyze the struggle for the land that ensues, involving peasants and southern producers called gauchos.

Keywords: Fight for land. Soy Expansion. Microregion Chapadinha. Maranhão. 


\section{Introdução}

Conforme documentos publicados pela Empresa Maranhense de Pesquisa Agropecuária (EMAPA), a partir dos anos 1970, o governo estadual já realizava esforços no sentido de inserir o cultivo da soja no território maranhense. Os primeiros estudos experimentais com a soja foram realizados pela Secretaria de Agricultura no ano de 1971, por meio de convênio entre a Superintendência de Desenvolvimento do Nordeste (SUDENE) e a Secretaria de Agricultura do Maranhão (SAGRIMA) (MARANHÃO, 1983).

A EMAPA foi criada em 1976, e a partir do ano de 1978, iniciou um programa de pesquisa com soja coordenado pelo Centro Nacional de Pesquisa de Soja (CNPSo), tendo por objetivo verificar a nível de campo, a adaptabilidade da cultura em algumas regiões do estado do Maranhão. As áreas selecionadas, três no total, foram: Bacabal (Cocais), Balsas (Planalto) e Brejo (Cerrados). Os estudos tiveram como prioridade a seleção de genótipos resistentes a doenças, pragas comuns e com boas características fenotípicas. Outros trabalhos referentes às práticas culturais também foram realizados, a exemplo da determinação de épocas de semeadura, correção do solo com calcário e fósforo, adubação com macro e micro elementos, entomologia e microbiologia (MARANHÃO, 1983).

Foi sugerida desse modo, a criação de dois grupos de áreas para a expansão da soja. 0 denominado Grupo I, com áreas no sul e sudoeste do Maranhão, incluindo as microrregiões de Imperatriz, Chapadas Sul do Maranhão e Baixo Balsas que se caracterizam pela utilização de áreas com fins puramente comerciais. E o Grupo II compreendendo as microrregiões do Baixo Parnaíba Maranhense, Mearim e Itapecuru caracterizadas pela utilização de pequenas áreas com o objetivo de propiciar alternativa de produção ao pequeno produtor, esperando-se inclusive, através de um programa de extensão rural, incluir o produto (a soja) na dieta alimentar do rurícola maranhense (MARANHÃO, 1983).

Dentre as justificativas apresentadas pelo governo estadual para a implantação da produção de soja no Maranhão estava o baixo desempenho da economia do estado que se assentava, fundamentalmente, no setor agropecuário voltado para a rizicultura e extrativismo do babaçu. Este último, à época, apresentava taxas decrescentes na sua oferta devido à excessiva devastação das palmeiras, comprometendo sobremaneira o parque industrial de oleaginosa e em consequência as atividades econômicas do estado. No que tange à 
atividade rizícola, a ausência de chuvas nos últimos quatro anos na região Nordeste e sua extensão rumo a Pré-Amazônia Maranhense a começar pelo Sul do Estado, tem provocado enormes prejuízos a produtores desta região habituados à monocultura do arroz (MARANHÃO, 1983).

No que se refere ao estabelecimento dos primeiros agricultores no sul do Maranhão, em especial no município de Balsas para desenvolvimento da cultura da soja, a literatura especializada indica que os primeiros produtores chegaram à região na década de 1970, para o desenvolvimento, inicialmente, do plantio de arroz (DINIZ, 1984; SOUZA FILHO, 1995; ALVES, 2006; PAULA ANDRADE, 2008; CARNEIRO, 2008; FERREIRA, 2008a; OLIVEIRA, 2011; MOTA, 2011).

No entanto, ao chegarem ao sul do estado, os denominados gaúchos ${ }^{1}$ vão se instalar em áreas onde um campesinato encontra-se enraizado há mais de dois séculos, ou seja, não se defrontam com áreas "livres", e sim com terras efetivamente ocupadas (PAULA ANDRADE, 2008). Nesse sentido, a implantação desses projetos agropecuários, inicialmente com a rizicultura e posteriormente com a soja, foram responsáveis pela expropriação, via apropriação fraudulenta das terras, de várias famílias camponesas para a zona urbana do município de Balsas ou para cidades maiores como Goiânia e Brasília (PAULA ANDRADE, 2008).

Nos anos 1980 são realizados os primeiros plantios com soja no sul do Maranhão, entretanto, é a partir dos anos 1990 que a região de Balsas se instrumentaliza para a produção de grãos em grande escala, através da intensificação da pesquisa científica, viabilizada pelo convênio de cooperação técnica e financeira (FERREIRA, 2008a; FERREIRA, 2009).

A partir de 1991, a pesquisa com a cultura da soja foi intensificada pela parceria com a CVRD, através da Superintendência da Estrada de Ferro Carajás. Além do convênio de

\footnotetext{
'É uma categoria genérica utilizada pela população local para se referir àqueles indivíduos oriundos de estados da região sul e sudeste do país. Há estudos no âmbito das Ciências Sociais e também da Geografia que discutem esta categoria. Para um maior aprofundamento desta categoria no âmbito das Ciências Sociais, Cf. PAULA ANDRADE, Maristela de. Os gaúchos descobrem o Brasil: projetos agropecuários contra a agricultura camponesa. - São Luís: EDUFMA, 2008. 226 p. GASPAR, Rafael B. O eldorado dos gaúchos: deslocamento de agricultores do Sul do país e seu estabelecimento no Leste Maranhense. - São Luís, EDUFMA, 2012. Na Geografia Cf. HAESBAERT, Rogério. Des-territorialização e identidade: a rede "gaúcha" no Nordeste. - Niterói: EDUFF, 1997. $293 p$
} 
cooperação técnico-financeira para custeio de pesquisa, ocorreram estudos conjuntos para criação do Programa Corredor de Exportação Norte embasados nos resultados de pesquisas realizadas pela EMBRAPA, da infraestrutura da CVRD na região, da presença de recursos humanos e de condições favoráveis à produção de grãos em larga escala (PALUDZYSZYN FILHO, 1995).

No ano de 1993 foi criada no município de Balsas, a Fundação de Apoio à Pesquisa do Corredor de Exportação Norte "Irineu Alcides Bays" (FAPCEN), tendo por objetivo representar os empresários, nas áreas de pesquisa e extensão privada, dos estados do Maranhão, Piauí e Tocantins. Esta empresa conta também com parceria da EMBRAPA SOJA, sendo fundamental no desenvolvimento de novas tecnologias e cultivares de soja adaptados às condições fisiográficas da região (FERREIRA, 2008b; OLIVEIRA, 2011).

Outro programa desenvolvido pelo Estado no sentido de estimular a produção de soja no sul do Maranhão foi o PRODECER III, criado no ano de 1995 e implantado no município de Balsas, mais especificamente na Serra do Penitente, se constituiu num grande investimento direcionado para ampliar a produção de grãos nessa parte do estado (SOUZA FILHO, 1995; GIORDANO, 1999; FERREIRA, 2008a; FERREIRA, 2008b; ALVES, 2006; LIMA, 2015).

A participação do referido programa no Maranhão limitou-se a um projeto de colonização agrícola, envolvendo quarenta famílias de agricultores, sendo vinte sulistas e vinte de outras regiões. Este projeto foi executado sob a coordenação da Cooperativa Agropecuária Batavo do Paraná, da Companhia de Promoção Agrícola (CAMPO) e do Banco do Nordeste (ALVES, 2006).

Convém ressaltar também que o PRODECER III implantado no sul do Maranhão, estava inserido dentro das chamadas políticas contemporâneas que, segundo Ferreira (2008b, p. 182) "são compreendidas como aquelas que o Estado pratica no intuito de facilitar e materializar a ocupação, apropriação e/ou exploração econômica".

O projeto Rodovias Brasil II foi outro programa direcionado para o sul maranhense no sentido de viabilizar a produção de soja na região. Segundo Souza Filho (1995), este programa, aprovado pelo Banco Mundial, foi responsável pelo melhoramento e pavimentação da estrada que liga os municípios de Balsas a Alto Parnaíba, com um 
orçamento de 79 milhões de dólares sob a responsabilidade do Departamento de Estradas de Rodagem do Maranhão (DERMA).

A partir dos anos 2000 ocorre o processo de expansão da área plantada com soja para outras regiões do Maranhão, a exemplo da mesorregião Leste Maranhense, incentivada por ações do governo estadual, através de estudos e pesquisas realizadas pela EMAPA em municípios da microrregião de Chapadinha, como será destacado posteriormente.

Assim, as situações acima descritas evidenciam que não se pode falar do processo de implantação da soja no território maranhense sem pensar no Estado e suas políticas públicas, que não somente viabilizaram sua origem como também sua expansão. Seja através da construção de infraestruturas (portos, rodovias, ferrovias), ou por meio de subsídios financeiros e pesquisa.

Nesse contexto, as iniciativas do Estado em parceria com a iniciativa privada foram responsáveis pela consolidação da produção de soja no município de Balsas e, posteriormente, sua expansão para outras regiões do estado.

\section{A expansão e consolidação da produção de soja no Leste}

\section{Maranhense}

A Mesorregião Leste Maranhense (Figura 01), segundo classificação do IBGE, é constituída por seis microrregiões geográficas, 44 municípios abrangendo uma área territorial de $70.606,230 \mathrm{~km}^{2}$, possuindo uma população total de 1.336.005 habitantes (IBGE, 2010).

Constitui-se numa grande área que se localiza próxima à divisa com o Piauí, limitada com este estado pelo Rio Parnaíba. Apresenta zonas geomorfológicas de contato entre os biomas cerrado e caatinga. A área de predomínio do cerrado abrange desde os municípios de Barreirinhas, Chapadinha, Urbano Santos, Vargem Grande, até a região sul, nos municípios de Balsas, Riachão e Carolina, apresentando relevo aplainado e chapadas (MUNIZ, 2002). Do ponto de vista das populações locais, tendo por referência a apropriação dos recursos, essa 
formação vegetal apresenta definições várias, como chapadas ${ }^{2}$, carrasco, baixão e capão (PAULA ANDRADE, et. al, 2012).

O Leste Maranhense já foi também objeto de distintas classificações politico-administrativas e destinada a diferentes apropriações econômicas. Segundo Paula Andrade et. al (2012), essa área, que integra o bioma cerrado, embora possa ser considerada, em relação aos recursos ambientais aí existentes, uma área de transição entre caatinga e floresta amazônica, já conheceu diferentes configurações em termos de suas fronteiras politicoadministrativas, assim como integrou distintas unidades de planejamento econômico ao longo do tempo (PAULA ANDRADE, et. al, 2012).

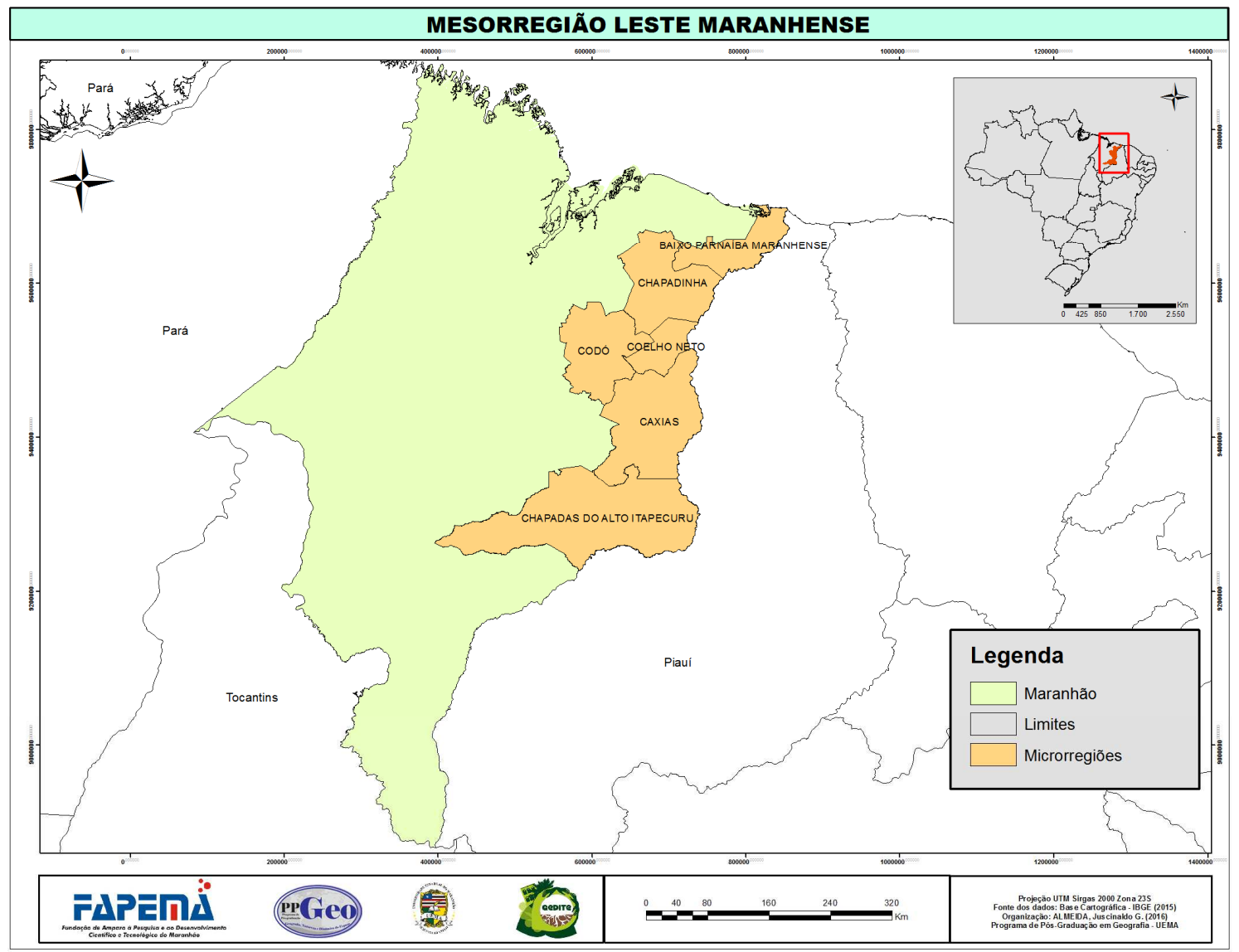

FIGURA 01 - Mapa de localização da Mesorregião Leste Maranhense FONTE: Organizado pelos autores a partir do IBGE (2015)

\footnotetext{
${ }^{2}$ De acordo com Paula Andrade (1995, p. 82), as áreas de chapadas são apropriadas pelas unidades de produção camponesa para a criação de gado bovino e de pequenos animais, para a caça e o extrativismo. Essas áreas sempre tiveram importância crucial no âmbito da economia dos diferentes segmentos camponeses. Frutos como o pequi, o cajuí, o murici, a mangaba; diferentes tipos de cocos e favas, assim como o mel, são fundamentais na composição da dieta das famílias camponesas, assim como para o fabrico do sabão, do óleo e de medicamentos tradicionais. O chamado capim agreste que brota na chapada, no começo da estação das águas é de grande importância para a criação do gado.
} 
Gaspar (2013) lembra que no período colonial a região Leste Maranhense foi ocupada por distintos grupos indígenas, tendo sua localização circunscrita principalmente à chamada Comarca de Brejo que compreendia as antigas Vilas de Brejo, de São Bernardo do Parnaíba e de Tutóia.

No tocante aos grupos indígenas, Assunção (2008) menciona que a região que compreende os rios Itapecuru e Parnaíba foi povoada, no litoral, pelos Tremembés; os Araioses e Anapurus, no Paranaíba; os Aracarés, no Preguiça; os Barbados, Gamelas e Tupinambás, no Itapecuru e adjacências e os Uruatis, Guanarés e Caicases, mais na região do Munim.

A região em questão foi denominada por Lopes (1970) de Maranhão oriental. De acordo com Assunção (2015), como as terras de matas propicias para a agricultura de exportação no Maranhão oriental eram poucas e de não fácil acesso, não atraíram maior atenção. É somente na segunda metade do século XIX, segundo o autor, que se encontram descrições mais elaboradas sobre o potencial agrícola do Maranhão oriental.

Nesse contexto, as terras mais valorizadas na região passaram a serem aquelas situadas próximas aos vales férteis dos rios Parnaíba, Buriti e Preguiças, e somente quando havia possibilidades de transporte para os produtos agrícolas. Já nas áreas de chapadas ou nas cabeceiras dos rios a terra praticamente não tinha valor (ASSUNÇÃO, 2015).

Assim, os cursos d'água, segundo Gaspar (2013), se constituíram em importantes caminhos para a movimentação da produção regional e a Vila de São João da Parnaíba (atual município de Parnaíba) situada no atual estado do Piauí, exercia, no século XIX, influência maior na região do que a capital São Luís em função da facilidade de escoamento da produção regional através dos rios maiores e navegáveis, a exemplo do Parnaíba.

A área que hoje compreende o Leste Maranhense foi ocupada por camponeses de diversas origens desde a primeira metade do século XIX, movimento esse que se estendeu ao Maranhão central e ocidental no século XX (ASSUNÇÃO, 2015).

Assunção (2015) destaca ainda que a migração nordestina no século XIX foi decisiva para a eclosão e extensão da Balaiada, importante movimento social ocorrido no Maranhão e que teve na região aqui enfocada, uma das principais áreas de ocorrência desta revolta. Desse modo: 
Os milhares de nordestinos, que se juntaram e eventualmente se misturaram como os caboclos, os escravos alforriados e seus descendentes, contribuíram para a formação de uma classe camponesa particularmente vigorosa no Maranhão oriental, que veio a constituir a base principal da revolta na área. Em contrapartida, o campesinato do Maranhão ocidental era constituído, na época, sobretudo por "índios domésticos", menos aculturados que os camponeses do golfo maranhense, núcleo antigo da colonização (ASSUNÇÃO, 2015, p. 104).

Desse modo, essa frente de expansão camponesa formada por indígenas destribalizados, descendentes forros e aquilombados de escravos africanos e migrantes nordestinos, sobretudo cearenses, foram incorporando novos territórios e se constituindo na base da formação do campesinato do Leste Maranhense (ASSUNÇÃO, 2008; 2015).

A formação desses territórios (Haesbaert, 2016) que em geral foram se constituindo nas imediações da plantation, levou ao desenvolvimento de sistemas de uso comum. Terras comunais e situações conhecidas atualmente como terras de preto, terras de santo e terras de índio estabeleceram-se muito antes da Abolição (ASSUNÇÃO, 2015; SOUZA FILHO, 2008).

Mesmo com a desestruturação das grandes unidades de produção, os camponeses aí permaneceram, adotando práticas especificas de uso da terra e dos recursos naturais, formando uma base econômica autônoma e independente da influência das grandes lavouras do passado (PAULA ANDRADE, 1995).

A partir das primeiras décadas do século XX, segundo Velho (2013), iniciou-se a entrada de um significativo fluxo de pessoas oriundas de outros estados do Nordeste no Maranhão em busca principalmente de terras, fugindo das secas e das dificuldades de colocação da mãonos seus locais de origem. Esse fluxo migratório, de acordo com Andrade (1973), foi feito de um modo geral por terra, atravessando o Rio Parnaíba em dois pontos, Teresina e Floriano. Os que chegam por Teresina se dirigem daí para Caxias. Na época do estio, quando os rios baixam e as planícies não estão inundadas, direcionam-se os migrantes para o Noroeste, seguindo o curso do Itapecuru ou para o Oeste à procura das áreas drenadas pelo Grajaú, pelo Mearim e pelo Pindaré (ANDRADE, 1973).

Nos anos 1990, Paula Andrade (1995), em trabalho de campo no Leste Maranhense, identificou a presença de pelo menos sete segmentos camponeses na região, sendo eles:

(...) os pequenos proprietários, que detêm o titulo da terra, em geral os homens mais velhos; os herdeiros da terra de herança sem partilha; os parentes desses herdeiros que, embora não tenham o direito a terra permanecem morando e cultivado nas terras dos parentes, nos limites do povoado; os parentes desses herdeiros que apenas residem nos limites desses povoados, mas pagam renda 
para cultivar em outras terras, de latifundiários ou de outros pequenos proprietários; os herdeiros de terras de herança que pagam renda para cultivar a terra em outras propriedades, quando suas terras encontram-se exauridas, ou que os limites do povoado só comporta as residências; os moradores de terras de preto , que as usufruem em comum; os herdeiros, ou pequenos proprietários que ocuparam terras de chapadas limítrofes às propriedades, tornando-se posseiros (PAULA ANDRADE, 1995, p. 34). (Grifos nossos).

O processo de territorialização desse campesinato ocorreu a partir da instalação das primeiras famílias e suas unidades residenciais e que posteriormente, deu origem aos chamados povoados, aglomerados de casas localizados de modo geral próximos a importantes cursos d'água da região (PAULA ANDRADE, et al, 2012).

O campesinato da região têm como principal atividade econômica o cultivo de alimentos básicos, a exemplo da mandioca, arroz e milho conjuntamente a extração de mel e, principalmente frutas nativas como o bacuri e o pequi, além da caça, pesca e criação de animais de grande e pequeno porte em áreas de cerrado denominadas baixão, capão e chapada (MORAES, 2009; PAULA ANDRADE, 1995; GASPAR, 2013).

Em algumas situações esta agricultura camponesa é realizada nas próprias chapadas, em manchas de solo que permitem o cultivo, cognominadas capões, morros e carrascos (PAULA ANDRADE et. al, 2012). Contrariando assim, interpretações de autores clássicos que apontavam as terras de cerrado como impróprias para a agricultura (ANDRADE, 1984).

Sendo assim, esses camponeses secularmente estabelecidos no leste do Maranhão, constituíram um modo de vida bastante singular, pautado em regras de relação com a terra e demais recursos da natureza. Desse modo, resultam de práticas organizadas, mobilização de recursos materiais e intelectuais de diferentes tipos, vinculados a contextos e situações especificas (SANTOS; MENESES; NUNES, 2005).

A partir dos anos 1980, essa região foi ocupada por grandes grupos econômicos, a exemplo do Grupo João Santos; Maranhão Gusa S/A (MARGUSA) e seu braço florestal, na época, a Maranhão Reflorestadora Ltda. (MARFLORA), Comercial e Agrícola Paineiras pertencente ao Grupo Suzano Papel e Celulose. Além disso, partir dos anos 1990, chegaram à região os chamados gaúchos (PAULA ANDRADE, 1995; CARNEIRO, 2008; GASPAR, 2013). A chegada desses agentes empresariais à região foi responsável pela desestruturação dos territórios camponeses por meio do processo de aquisição de terras através de atos ilícitos (SHIRAISHI NETO, 1995), desmatamento do cerrado e expropriação de moradores dos seus povoados. 


\section{A dinâmica do agronegócio da soja na região}

Chapadinha, uma das seis microrregiões que formam a Mesorregião Leste Maranhense, apresenta uma área territorial de $10.030,543 \mathrm{~km}^{2}$ e uma população total de 219.825 habitantes (IBGE, 2010). É composta por nove municípios, sendo eles: Anapurus, Belágua, Brejo, Buriti, Chapadinha, Mata Roma, Milagres do Maranhão, São Benedito do Rio Preto e Urbano Santos.

A microrregião de Chapadinha é, segundo a literatura especializada, a região, no Leste Maranhense, que se destaca na produção sojícola, concentrada principalmente nos municípios de Brejo, Buriti, Anapurus e Mata Roma (CARNEIRO, 2008; GASPAR, 2013; GUIMARÃES, 2012; ALMEIDA, 2014; NASCIMENTO, 2011).

A introdução e expansão da produção de soja para a região é considerada recente, estando relacionada aos trabalhos de pesquisa realizados pela EMBRAPA e EMAPA, num primeiro momento e, posteriormente, a iniciativas dos chamados gaúchos e também das empresas que lá se instalaram como a Prio e SLC. A introdução de cultivos experimentais se inicia na primeira metade da década de 1990 e a partir do seu final, se expandirá com vistas à comercialização no exterior.

Gaspar (2013) em estudos sobre os deslocamentos dos denominados gaúchos e seu estabelecimento no Leste Maranhense, destaca que a vinda destes produtores para a região não ocorreu por meio de projetos de colonização oficial a exemplo das famílias sulistas que migraram nas décadas de 1960 e 1970 para o Centro-Oeste do País e Sul do Maranhão. Ainda segundo o autor, não se pode falar, de uma espécie de ramificação daqueles que já se encontravam no Sul do Maranhão em direção ao Leste do estado (GASPAR, 2013).

Convém mencionar que, nos anos 1980, o governo do Maranhão, por meio da EMAPA, já vinha desenvolvendo experimentos com soja na região, implantado inclusive, no município 
de Brejo, a Unidade de Execução e Pesquisa de Âmbito Regional ${ }^{3}$ (UEPAR) (MARANHÃO 1983).

Tal situação relativiza a ideia de que os denominados gaúchos foram os pioneiros no desenvolvimento da sojicultura na região, demonstrando que anteriormente, o Estado já tomara a iniciativa de pesquisar acerca da viabilidade do cultivo desta leguminosa nesta parte do estado. Demonstra também que o discurso de "modernização e pioneirismo" (HAESBAERT, 1997) acompanha esses agentes no tocante ao seu deslocamento e o desenvolvimento do agronegócio nas áreas de cerrado do Norte/Nordeste.

Após seu estabelecimento na microrregião de Chapadinha, os gaúchos se apropriaram das áreas de chapadas que foram vendidas por latifundiários da região a preços baixos. Nesse contexto, os plantios de soja foram abertos pelos caminhos tradicionais de circulação dos camponeses que ligam povoados e estes às sedes municipais. Os moradores desses locais percebem essa disposição fazendo uso de expressões como viver circulado, estar em círculo, habitar no círculo, opondo essa maneira de utilização das chapadas ao regime agrícola de uso comum que predominava tradicionalmente entre elas (GASPAR, 2013).

A partir dos anos 2000, a produção de soja no Leste Maranhense e, em especial na microrregião de Chapadinha avança em diferentes municípios, tendo como fatores de atração sua proximidade em relação ao Porto do Itaqui, a possibilidade de escoamento da produção agrícola através da BR - 222, a crescente liberação de credito rural (CAMPELO, 2000; CARNEIRO, 2008; GASPAR, 2013) e, recentemente, a inauguração do Terminal de Grãos do Maranhão(TEGRAM).

A própria EMBRAPA em comunicado técnico intitulado Vantagens competitivas da exploração da soja no cerrado do Nordeste do Maranhão aponta as chamadas vantagens que a região do cerrado da microrregião de Chapadinha apresenta em relação a outras áreas tradicionais de cultivo da soja, como o sul do Maranhão e sudoeste do Piauí, como por exemplo:

\footnotetext{
${ }^{3}$ A área programa da Unidade de Execução de Pesquisa de Âmbito Regional (UEPAR - Brejo) compreendeu os municípios de Araioses, Magalhães de Almeida, São Bernardo, Santa Quitéria, Brejo, Buriti, Duque Bacelar e Coelho Neto, pertencente à Microrregião do Baixo Parnaíba Maranhense, segundo classificação da FIBGE. Cf. MARANHÃO. EMPRESA MARANHENSE DE PESQUISA AGROPECUÁRIA - EMAPA. Área programa para unidade de execução de pesquisa de âmbito regional de Brejo - UEPAR - BREJO. São Luís, 1984.
} 
(...) o preço da terra (que são inferiores aos valores cobrados atualmente na região tradicional); a distância, tomando como base o Município de Chapadinha ao porto de Itaqui (aproximadamente $250 \mathrm{~km}$ ) reduzindo o preço do transporte em relação às regiões tradicionais (Balsas, MA ou de Bom Jesus, $\mathrm{PI}$ ) e a época de plantio que é diferenciada, ocorrendo somente a partir de meados de janeiro. Essa época não concorre com o plantio da região sul do Maranhão ou sudoeste do Piauí, onde o plantio ocorre entre 15 de novembro e 15 de dezembro. A diferença de 30 dias, propicia aos empresários a exploração simultânea do cerrado sul do Maranhão ou sudoeste do Piauí e o cerrado nordeste do Maranhão, sem novos investimentos de máquinas e implementos agrícolas, tornando o seu agronegócio mais rentável (CAMPELO, 2000, p. 2).

No tocante aos agentes que desenvolvem atividades relacionadas à produção e comercialização da soja na microrregião de Chapadinha, seja na produção ou comercialização, Gaspar (2013) destaca a atuação de produtores concentrados em dimensões de terra que, geralmente, variam entre 500 a 3.000 hectares, enquanto as empresas instaladas, as chamadas tradings, já dominam uma parcela maior de hectares.

A SLC Agrícola foi uma das primeiras empresas a ser instalada na microrregião de Chapadinha, mais precisamente no município de Buriti (Fazenda Palmeira), embora não se encontre mais na região após a venda de sua propriedade. Ademais, existem, também, na região, escritórios das multinacionais Cargill, Bunge, CHS e do grupo nacional Algar Agro, ambos sediados às margens da BR - 222 no município de Anapurus, além da Parceria Agropecuária Strobel, empresa sediada na Fazenda Europa , no município de Mata Roma.

\section{A luta pela terra frente à expansão da soja na Microrregião de}

\section{Chapadinha - MA}

Dentre as consequências mais claras da expansão da soja para o Leste Maranhense, uma é o agravamento da concentração da posse da terra. De acordo com Carneiro (2008) este processo ocorre através de múltiplos mecanismos, não estando diretamente relacionada ao uso da violência física, característica principal da expansão da fronteira agrícola brasileira.

Desse modo, por conta dessa característica, o numero de conflitos pela terra registrados pela Comissão Pastoral da Terra (CPT) na microrregião de Chapadinha não tem uma dimensão tão elevada quanto à observada em outros períodos da expansão do agronegócio e da luta pela terra no estado do Maranhão (CARNEIRO, 2008). 
Assim, por meio dos dados disponibilizados pela CPT fizemos um levantamento das informações de conflitos por terra para os municípios da microrregião de Chapadinha levando em conta o marco espaço temporal de analise do presente artigo. No período compreendido entre os anos de 2000 a 2005 a CPT registrou a ocorrência de 25 situações de conflito ${ }^{4}$ pela terra na microrregião de Chapadinha envolvendo 801 famílias. Dentre os municípios da região, Chapadinha foi aquele que apresentou o maior número de conflitos, 10 no total.

A partir do ano de 2010 se observa a maior eclosão de conflitos por terra na região, sendo registrado até 2015, 134 ocorrências, envolvendo 4.935 famílias, concentrando-se principalmente nos municípios de Urbano Santos (48 ocorrências com 2.182 famílias envolvidas) e Belágua (34 casos abrangendo 1.085 famílias). No município de Brejo, o maior número de conflitos por terra aconteceu também, nos anos 2010 em diante, 34 ocorrências contra 5 apontadas para o período 2000 a 2005.

Das situações litigiosas apontadas pela CPT para o município de Brejo destacam-se: os conflitos registrados nos povoados Pacuti e Santa Tereza cuja mobilização camponesa pela permanência na terra resultou na criação de projetos de assentamento de reforma agrária; a situação das comunidades pertencentes ao Território Quilombola de Saco das Almas, a exemplo de São Raimundo/Boa Esperança que buscam na afirmação da identidade étnica uma importante bandeira de luta contra o agronegócio; o caso do povoado São João dos Pilões que tem no artesanato com madeiras do cerrado um importante meio de vida e que tem entrado em litígio com os chamados gaúchos ${ }^{5}$ pela utilização das áreas de chapadas.

No caso dos municípios de Chapadinha, Belágua e Urbanos Santos que, conforme dados da CPT apresentaram o maior número de conflitos por terra no período enfocado, tal situação está relacionada, no caso do primeiro, a questões litigiosas contra os chamados gaúchos e proprietários tradicionais que tem tentado limpar suas pretensas terras de moradores

\footnotetext{
${ }^{4} \mathrm{~A}$ não indicação pela CPT, de ocorrência de conflitos por terra na microrregião de Chapadinha nos anos anteriores, de forma alguma pode ser interpretada como de ausência de situações litigiosas na região. A ausência de informações por parte da CPT para os anos destacados pode está relacionado a pouca atuação do órgão na região naquele período ou ainda devido às dificuldades de obtenção de informações a época.

${ }^{5}$ Para uma visão mais detalhada acerca do conflito no povoado São João dos Pilões Cf. VIEIRA, Anderson S. Gaúchos e Herdeiros: identidade e território na chapada maranhense. 75 f. Monografia (Graduação em Ciências Sociais). Universidade Federal do Maranhão, São Luís, 2009.
} 
antigos (CARNEIRO, 2008). Já no caso dos dois últimos, os conflitos estão diretamente relacionados às atividades desenvolvidas pela Suzano Papel e Celulose e suas terceirizadas.

As informações disponibilizadas pela CPT apontam ainda que a principal categoria social envolvida nas situações de conflitos por terra na Microrregião de Chapadinha são os posseiros. Tal situação se justifica pelo fato de serem os camponeses que habitam principalmente as áreas de posse, os mais afetados pela expansão da sojicultura e outros monocultivos florestais na região, uma vez que desprovidos do documento de comprovação da propriedade da terra se tornam o elo mais frágil do processo de concentração fundiária (CARNEIRO, 2008).

Nessa conjuntura, conflitos entre gaúchos e camponeses são registrados em vários municípios da microrregião de Chapadinha. Estes estão relacionados principalmente aos atos de grilagem de terras, desmatamento das chapadas e o consequente desaparecimento das várias atividades desempenhadas pelos camponeses naquele ambiente, a exemplo da criação de animais, caça, coleta de frutos e plantas medicinais. Outras questões referem-se ao envenenamento de recursos hídricos ocasionando a morte de peixes e animais domésticos, por conta dos agrotóxicos colocados nos campos de soja. Estes são problemas relatados de forma recorrente por camponeses alcançados pela expansão da soja na região, como demostrado em estudo conduzido por Paula Andrade et al (2012) em povoados dos municípios de Santa Quitéria do Maranhão, Mata Roma e Urbano Santos.

Barroso (2012) e Silva Júnior (2011) em estudos realizados no município de Buriti demonstraram também a ocorrência de conflitos entre gaúchos e camponeses. De acordo com Barroso (2012), em pesquisa empírica desenvolvida no povoado Matinha, a primeira situação de conflito ocorrida foi quando os tratores chegaram ao local para dar início ao desmatamento da chapada, área que à época pertencia a Fazenda Boa Esperança. A partir desse momento, de acordo com o autor, os camponeses munidos de armas (facões e espingardas) tentaram impedir o desmatamento da área gerando um clima de forte tensão que só foi resolvida com a chegada de policiais militares do município de Chapadinha.

Já a pesquisa desenvolvida por Silva Júnior (2011) no povoado Valença, situado também no município de Buriti, demonstrou como o desmatamento das chapadas afetou diretamente os camponeses com a perda de áreas tradicionais de extrativismo. De acordo com o autor, a 
abertura dos chamados campos de soja alterou também os caminhos tradicionalmente utilizados pelos camponeses para deslocamentos a áreas de cultivo e povoados vizinhos.

Apesar da forte presença de atividades ligadas ao ramo da silvicultura e da soja na microrregião de Chapadinha e as consequências negativas da atuação desses empreendimentos para os camponeses observa-se que as diversas modalidades de reordenamento fundiário, denominadas ações de reforma agrária realizada pelo Instituto Nacional de Colonização e Reforma Agrária (INCRA) e Instituto de Colonização e Terras do Maranhão (ITERMA) é bastante tímida na região (CARNEIRO, 2008).

No período de 1990 a 2015, conforme informações do INCRA, foram criados 43 projetos de assentamentos rurais (estaduais e federais) nos municípios pertencentes à microrregião de Chapadinha comprovando a fraca atuação na região, dos órgãos responsáveis pelas políticas de ordenamento fundiário.

No período de 1990 a 2000 em toda a microrregião foram criados apenas 10 projetos de assentamentos que juntos beneficiaram 783 famílias. No entanto, dos anos 2001 em diante os dados do INCRA apontam para um crescimento expressivo do número de assentamentos rurais na região, 33 no total assentando 2.279 famílias, o que de certa forma já demonstra uma movimentação camponesa para a permanência na terra/território, tendo em vista que, no Maranhão, os assentamentos são resultado da ação das próprias famílias de posseiros, pequenos arrendatários, foreiros que, em muitos casos, lutaram para continuar na terra tendo, muitos deles, sido assassinados em decorrência dessa luta (CARNEIRO et al, 1996).

Destarte, no caso do Maranhão, o que se está chamando de assentamentos, seja nas áreas de ocupação mais recente, a exemplo da Pré-Amazônia Maranhense, ou em áreas antigas, nada mais são do que povoados camponeses tal como sempre existiram (CARNEIRO et al, 1996). No caso específico da microrregião de Chapadinha, segundo Araújo (2015), a característica comum dos assentamentos é que as famílias assentadas na grande maioria já moravam na área posteriormente desapropriada ou muito próxima dela.

Dentre os municípios da microrregião, Chapadinha (10 projetos), São Benedito do Rio Preto (10 projetos) e Urbano Santos (7 projetos) foram aqueles que apresentaram no período de análise o maior número de projetos de assentamentos rurais criados. Brejo e Buriti, municípios que lideram a produção de grãos na região, apresentaram respectivamente, seis 
e três projetos criados, demonstrando que é justamente nas áreas de forte presença do agronegócio que as ações de reforma agrária, quando existentes se apresentam de forma bastante insignificante.

Apesar da pouca atuação dos órgãos de regularização fundiária na região, torna-se importante destacar a luta dos camponeses contra a ameaça de expropriação pelo agronegócio por meio de ações coletivas para manutenção dos seus territórios. Situações como estas se caracterizam como de retomada de ações defensivas que marcaram as lutas sociais nos anos 1970/1980, com a organização de movimentos específicos de defesa da terra, a exemplo da mobilização realizada pelo Fórum em Defesa da Vida no Baixo Paranaíba Maranhense (FDVBPM), do Movimento Quilombola Maranhense, além da continuação das ações lideradas por STTR's (CARNEIRO, 2013, p. 31).

Dentre as várias ações destaca-se a mobilização camponesa para criação da Reserva Extrativista Chapada Limpa no município de Chapadinha (SOUZA FILHO, 2014; MENDES, 2015). Conforme Souza Filho (2014) questões como: a cobrança abusiva do aluguel da terra para implantação dos roçados das famílias do povoado Chapada Limpa I por um pretenso proprietário; o conflito no povoado Chapada Limpa II, acontecido no ano de 2004, que resultou na supressão da cobertura florestal nativa e na derrubada de um bacurizeiro, por outro suposto proprietário de terras; além da ameaça de derrubada de áreas de chapada no povoado Juçaral para plantio de soja, no ano de 2004, são apontadas como situações-limite para mobilização coletiva das famílias em defesa das áreas.

Souza Filho (2014) e Mendes (2015) aludem que num desses momentos de ameaça de desmatamento das chapadas, camponeses dos povoados de Chapada Limpa I, Juçaral e Chapada Limpa II, munidos de facões, foices e outros instrumentos de trabalho se dirigiram até onde se localizavam os tratores, impedindo sua passagem, ameaçando até mesmo incendiar as máquinas caso os encarregados prosseguissem com o trabalho.

Dessa forma, com base na demanda das Associações de Moradores de Chapada Limpa I, Chapada Limpa II, Juçaral e do STTR de Chapadinha,

(...) o Centro Nacional de Populações Tradicionais e Desenvolvimento Sustentável (CNPT) realizou estudos na região no sentido de verificar as condições para criação da unidade de conservação. Os trabalhos do CNPT identificaram na zona reivindicada pelas famílias inúmeras nascentes de rios que poderiam ser comprometidas caso os plantios de soja fossem instalados na região. Em julho de 
2006, foi realizada uma Consulta Pública em Chapadinha, na qual foi apresentada a proposta de criação da unidade de conservação (SOUZA FILHO, 2014, p. 54).

Destarte, no ano de 2007, o então presidente Luiz Inácio Lula da Silva assinou o decreto de criação da Reserva Extrativista Chapada Limpa, unidade de conservação de uso sustentável localizada no município de Chapadinha, com uma área de 11.971,24 hectares beneficiando ao todo dezessete povoados (CARNEIRO, 2008; SOUZA FILHO, 2014; MENDES, 2015).

Além da concentração fundiária, da interdição do uso das chapadas, ocasionada pelo avanço da soja, outro problema enfrentado pelos camponeses da região diz respeito à redução da área plantada e, por conseguinte, a diminuição da produção agrícola de produtos como arroz e mandioca, fundamentais na dieta alimentar destes grupos. Situação visivelmente identificada na microrregião de Chapadinha, como explicitado no gráfico da área plantada (Gráfico 1) e quantidade produzida (Gráfico 2) dos produtos aludidos.

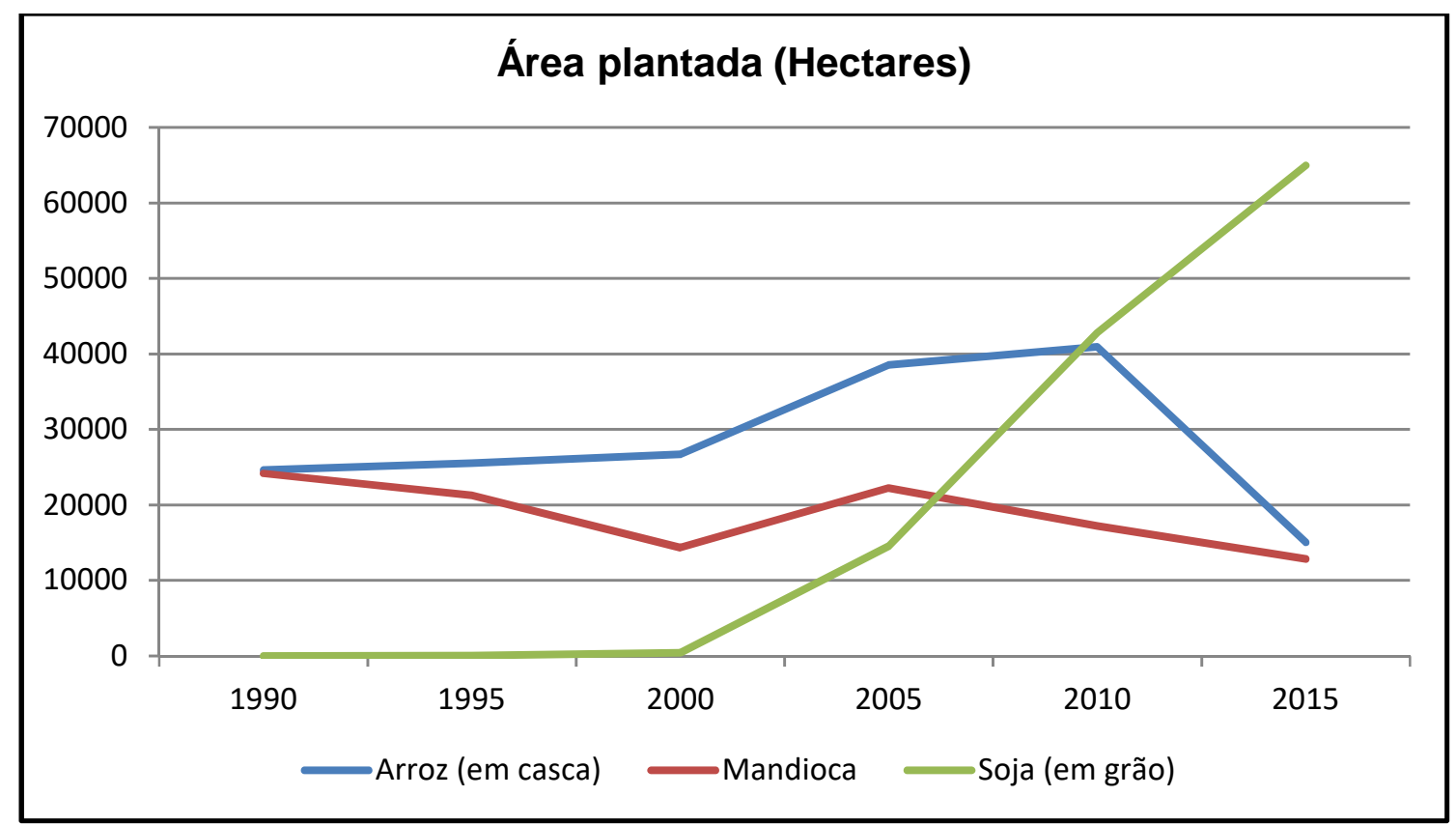

GRÁFICO 1 - Dinâmica da área plantada com arroz, mandioca e soja na Microrregião de Chapadinha - MA (1990 - 2015). FONTE: SIDRA/IBGE.

Somado aos diversos problemas advindos com a expansão da soja, já relatado em diversas passagens deste trabalho, a diminuição da área plantada e, por conseguinte, da produtividade dos referidos produtos da agricultura camponesa pode está relacionada também ao colapso do sistema de corte e queima no estado (GUSMÃO, 2009; FERRAZ JUNIOR et al, 2006). Fatores como a concentração fundiária e o uso da terra como reserva 
de valor contribuiu para o desequilíbrio do sistema de corte e queima. A diminuição do tempo de pousio em solos de baixa fertilidade natural, não permite uma restauração da produtividade das áreas destinadas ao cultivo resultando em lavouras menos produtivas (FERRAZ JUNIOR et al, 2006).

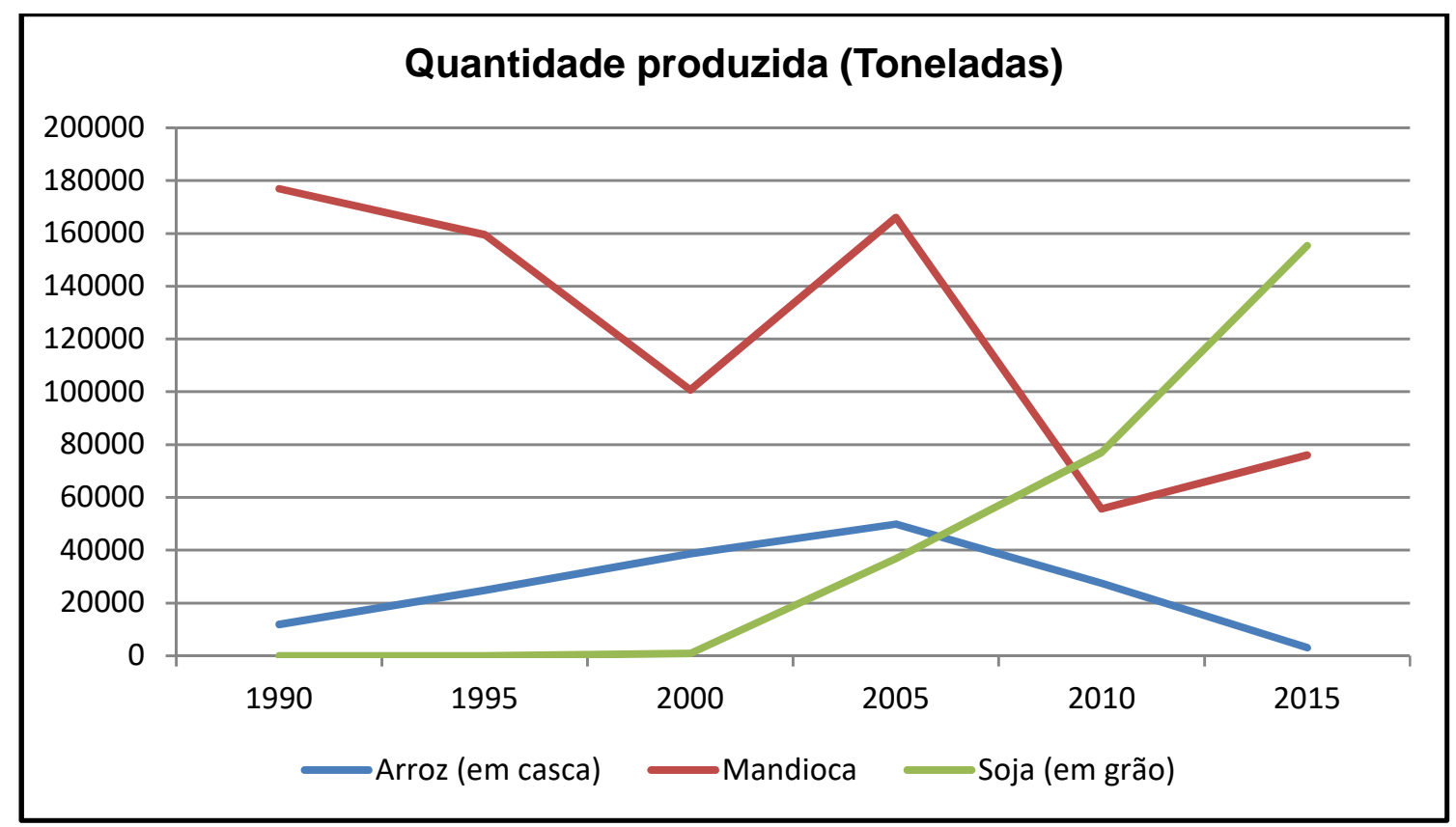

GRÁFICO 2 - Quantidade produzida de arroz, mandioca e soja na Microrregião de Chapadinha - MA (1990 - 2015). FONTE:SIDRA/IBGE.

No âmbito municipal observa-se que a maior desproporcionalidade está justamente naqueles que se destacam na produção sojícola na região, a exemplo de Buriti e Brejo, levando-se a conclusão que a agricultura camponesa desses locais está passando por um verdadeiro processo de asfixia à medida que a produção de grãos, sobretudo da soja, vem se expandindo nos últimos anos.

Alentejano (2011) analisando a dinâmica da agropecuária brasileira chama atenção para o decréscimo da área plantada com alimentos básicos à medida que aumenta a área destinada a cultivos destinados majoritariamente a exportação e a fins industriais. De acordo com o autor, no período de 1990 a 2006, a área destinada à produção de três alimentos básicos na dieta da população brasileira (arroz, mandioca e feijão) reduziu-se em mais 2,5 milhões de hectares (ALENTEJANO, 2011). 
Apesar de dispor de uma área agrícola menor, a agricultura camponesa segundo Fernandes (2012), reúne a maior parte do pessoal ocupado se comparado ao agronegócio. Ainda segundo o autor, essa disparidade se torna mais evidente quando se observa a relação pessoa/hectare que no território do agronegócio é de, em média, apenas duas pessoas para cada cem hectares, enquanto nos territórios camponeses a relação é de quinze pessoas para cada cem hectares.

Assim sendo, essa diferença de acordo com Fernandes (2012) revela as distintas formas de uso dos territórios pelo agronegócio e campesinato. Se para o primeiro a terra é somente lugar de produção, para o segundo é lugar de produção e moradia, características importantes para conceber o campesinato e o agronegócio como diferentes modelos de desenvolvimento territorial (FERNANDES, 2012).

No tocante aos produtos analisados nos gráficos anteriores, a cultura da mandioca merece destaque haja vista sua importância em termos absolutos, pois, de acordo com Carneiro (2008), trata-se do produto agrícola mais colhido, assim como por sua importância para a estabilidade da economia camponesa regional.

Desse modo, apesar da desorganização territorial e social imposta a partir da expansão da soja na microrregião de Chapadinha cujos efeitos negativos aparecem em situações como o aumento da concentração fundiária, a perda da biodiversidade e insegurança alimentar, é mister salientar os processos de luta pelo território em curso levado a cabo pelos camponeses da região. Processos estes que podem ser pensados a partir das praticas locais materializadas na relação com a terra/território ou ainda por meio do acionamento de novas identidades, a exemplo de quilombolas, extrativistas ou assentados de reforma agrária.

\section{Considerações finais}

O modelo agroexportador ainda se constitui na principal política dita de desenvolvimento adotada pelo Brasil como forma de crescimento econômico. Esta prática que teve início no chamado período colonial onde o país foi um dos principais fornecedores de produtos 
(agrícolas principalmente) para o mercado europeu e que teve como marcas principais a concentração da terra e a exploração do trabalho escravo.

Este tipo de modelo produtivo apesar de apresentar novas roupagens ainda perdura no país apresentando as mesmas características do período colonial que é a intensificação da concentração da terra, a produção para exportação e a expropriação do camponês da terra.

A partir da década de 1970, com aplicação do pacote tecnológico na agricultura que significou aumento da produção e da produtividade por meio da intensificação do uso da terra via utilização de implementos agrícolas, produtos químicos diversos e maquinário, o campo brasileiro passou por profundas modificações.

Por meio de diversos programas governamentais, as áreas de cerrado do país foram uma das regiões que recebeu a maior carga de investimentos direcionados para sua inserção no mercado globalizado via produção de grãos.

Nessa conjuntura, destacam-se as várias políticas territoriais direcionadas pelo Estado para dotar as regiões de infraestruturas para facilitar a expansão das diversas atividades vinculadas ao agronegócio. A exemplo dos investimentos em pesquisa científica por meio da criação de empresas como a EMBRAPA; a liberalização do crédito por meio de programas como o PRODECER. E mais recentemente, tem-se a continuidade dessas ações de fortalecimento do agronegócio a partir de iniciativas do governo brasileiro por meio da instituição do MATOPIBA.

Este (re) ordenamento pelo qual passou as áreas de cerrado provocou consequências diretas no modo de vida de diversas populações que há várias gerações desenvolvem distintas atividades como agricultura, extrativismo, caça, pesca dentre outras.

No contexto específico do Maranhão, a exemplo do Sul e Leste do estado, a expansão da soja sobre as áreas de cerrado trouxe significativas alterações na forma como os camponeses se relacionam com seus territórios. Dentre as principais mudanças destaque para a apropriação privada das áreas de chapadas que outrora eram utilizadas livremente para a caça, agricultura e extrativismo.

Além do uso material das áreas de chapadas enquanto território fonte de recursos, usufruído tanto por humanos como por outros animais, destaca-se o seu lado imaterial, a 
partir de uma dimensão simbólica e mais subjetiva (HAESBAERT, 2016), sendo utilizado também, como local de repouso para os mortos.

Com a expansão deste modelo agrícola baseado na monocultura de grãos, se confrontam dois modos distintos na forma como o território é apropriado. O território da soja tem como lógica a exploração intensiva da terra e do trabalho visando sempre o aumento do lucro, aqui a terra é vista como valor de troca. Do outro lado, o território camponês é caracterizado pela heterogeneidade da produção, por meio do cultivo de vários produtos num mesmo local, tendo por objetivo o consumo familiar e a comercialização do excedente. Assim, a terra tem como fim imediato o seu valor de uso.

A intensa utilização dos cerrados para produção de grãos, além da concentração da terra, desmatamento, poluição dos recursos hídricos, traz para o camponês a possibilidade de expropriação e perda do seu território e com ele, todo um sistema de conhecimento desenvolvido na relação com a natureza e no uso racional dos diversos recursos que esta dispõe.

Por meio da presente investigação observou-se que apesar do forte crescimento da área plantada com soja nos últimos anos na microrregião de Chapadinha, os camponeses têm desenvolvido distintas formas de estratégias para permanência na terra.

No entanto, é importante levar em consideração que as estratégias de luta pela terra, desenvolvidas pelos camponeses não ficam restritas apenas aos conflitos mais diretos. Assim, considera-se a existência de formas mais silenciosas de resistência (SCOTT, 2002). Essas formas silenciosas de resistência são expressas também na manutenção de um modo de vida específico, apesar de todas as adversidades trazidas pela expansão do agronegócio para o território camponês.

\section{Referências bibliográficas}

ALENTEJANO, Paulo. Questão Agrária no Brasil do Século XXI:uma abordagem a partir da Geografia. Revista Terra Livre, São Paulo. n.36, 2011, p.69-95.

ALMEIDA, Juscinaldo. Resistências territoriais desencadeadas a partir da implantação e expansão da soja no município de Brejo - MA. 103 f. Monografia (Graduação em Geografia) - Departamento de Geociências, Universidade Federal do Maranhão, São Luís, 2014. 
ALVES, Vicente. Mobilização e modernização nos cerrados piauienses: formação territorial no império do agronegócio. 320 f. Tese (Doutorado em Geografia Humana) - Programa de Pós-Graduação em Geografia, Universidade de São Paulo, 2006.

ANDRADE, Manuel Correia de.Paisagens e problemas do Brasil. 4ạ ed. - São Paulo: Brasiliense, 1973.

ANDRADE, Manuel Correia de. Ensaios sobre a realidade maranhense. São Luís: IPES, 1984.

ARAÚJO, Francisco. Desafios da reforma agrária, no contexto do desenvolvimento dependente no Estado do Maranhão: um estudo de caso da Microrregião de Chapadinha. 160 f. Dissertação (Mestrado Profissional) Programa de Pós-Graduação em Agroecossistemas, UFSC/Florianópolis, 2015.

ASSUNÇÃO, Matthias. A Guerra do Bem-te-vis: a Balaiada na memória oral. 2a ed. - São Luís: EDUFMA, 2008.

ASSUNÇÃO, Matthias. De Caboclos a Bem-te-vis: formação do campesinato numa sociedade escravista: Maranhão, 1800-1850. - São Paulo: Annablume, 2015.

BARROSO, Alex. A roça sem cerca e o cerco da soja: uma análise dos impactos sociais e ambientais causados pela sojicultura em Matinha - Buriti-MA. 89 f. Monografia (Graduação em Ciências Sociais) - Curso de Ciências Sociais. Universidade Federal do Maranhão. São Luís, 2012.

CAMPELO, Gilson. Vantagens competitivas da exploração da soja no cerrado do Nordeste do Maranhão. Comunicado Técnico. Embrapa Meio-Norte, 2000.

CARNEIRO, Marcelo; PAULA ANDRADE, Maristela de; MESQUITA, Benjamim. A reforma da miséria e a miséria da reforma: notas sobre assentamentos e ações chamadas de reforma agrária no Maranhão. Revista de Políticas Públicas. São Luís/MA. v.2, n.2, jul./dez. 1998, p. 101-130.

CARNEIRO, Marcelo. A expansão e os impactos da soja no Maranhão. In: SCHLESINGER, S.; NUNES, S. P.; CARNEIRO, M. S. (Orgs.). A agricultura familiar da soja na região Sul e o monocultivo no Maranhão: duas faces do cultivo da soja no Brasil. - Rio de Janeiro: FASE, 2008, p.75-143.

CARNEIRO, Marcelo. Terra, trabalho e poder: conflitos e lutas sociais no Maranhão contemporâneo. - São Paulo: Annablume, 2013.

DINIZ, JoseAlexandre. Modernização e conflito na fronteira ocidental do Nordeste. Revista GeoNordeste, Sergipe, n. 01, 1984, p. 12-20.

FERNANDES, BernardoMançano. Disputas territoriais entre movimentos camponeses e agronegócio. In: AYERBE, L. F. (Org.). Territorialidades, conflitos e desafios à soberania estatal na América Latina. São Paulo: Fundação Memorial da América Latina, 2012. p. 203-227.

FERREIRA, Maria da Gloria. A dinâmica da expansão da soja e as novas formas de organização do espaço na região de Balsas - MA. 276 f. Tese (Doutorado em Geografia) - Instituto de Geociências, Universidade Federal do Rio de Janeiro, 2008.

FERREIRA, Antonio Jose. Políticas territoriais e a reorganização do espaço maranhense. $269 \mathrm{f}$. Tese (Doutorado em Geografia Humana). Faculdade de Filosofia, Letras e Ciências Humanas. Universidade de São Paulo, 2008b.

FERREIRA, Maria da Glória. Repercussões da expansão da agricultura moderna sobre a pequena produção no Sul do Maranhão. In: BERNARDES, J. A.; BRANDÃO FILHO, J. B. (Orgs.). Geografias da soja II: a territorialidade do capital. - Rio de Janeiro: Arquimedes Edições, 2009. p. 67-88.

GASPAR, Rafael. O eldorado dos gaúchos: deslocamento de agricultores do Sul do País e seu estabelecimento no Leste Maranhense. São Luís: EDUFMA, 2013.

GIORDANO, Samuel. Competitividade regional e globalização. 249 f. Tese (Doutorado em Geografia) Faculdade de Filosofia, Letras e Ciências Humanas. Universidade de São Paulo, 1999.

GUIMARÃES, Alanildo. Dinâmica agrícola do cerrado da Microrregião de Chapadinha - MA: sua inserção no município de Anapurus. 129 f. Dissertação (Mestrado) - Programa de Pós-Graduação em Desenvolvimento Socioespacial e Regional. Universidade Estadual do Maranhão, São Luís, 2012.

GUSMÃO, L. A. (2009) Os desafios da introdução de uma inovação tecnológica no agroextrativismo tradicional: análise do caso das roças orgânicas no Médio Mearim. 150 f. Dissertação (Mestrado em Agroecologia). Curso de Mestrado em Agroecologia. Universidade Estadual do Maranhão. São Luís. 
FERRAZ JUNIOR, A. S. L.; MOURA, E. G.; AGUIAR, A. C. F. Plantio direto na palha de leguminosas em aléias uma alternativa para o uso sustentável dos solos do trópico úmido. In: MOURA, E.G.; AGUIRA, A.C.F. (Orgs.). O desenvolvimento rural como forma de ampliação dos direitos no campo: princípios e tecnologias. - São Luís: UEMA. Série Agroecologia - Vol. III, 2006. p. 221-238.

HAESBAERT, Rogerio. Des-territorialização e identidade: a rede "gaúcha" no Nordeste. Niterói, Rio de Janeiro: EDUFF, 1997.

HAESBAERT, Rogerio. O mito da desterritorialização: do "fim dos territórios" à multiterritorialidade. 9a ed. Rio de Janeiro: Bertrand Brasil, 2016.

LIMA, Debora. A expansão da fronteira agrícola moderna nos cerrados do centro-norte e o avanço dos monocultivos de soja no Tocantins. In: ALVES, V. L. A. (Org.). Modernização e regionalização nos cerrados do Centro-Norte do Brasil. - Rio de Janeiro: Consequência Editora/FAPESP, 2015. p. 325-351.

LOPES, Raimundo. Uma Região Tropical. Rio de Janeiro: Ed. Fon-Fon e Seleta, 1970.

MARANHÃO.Empresa Maranhense de Pesquisa Agropecuária. Área programa para unidade de execução de pesquisa de âmbito regional de Brejo - UEPAR - BREJO. São Luís, 1984.

MARANHÃO. Empresa Maranhense de Pesquisa Agropecuária. Subsídios para um programa de expansão da cultura da soja no estado do Maranhão. São Luís, 1983.

MATTOS JUNIOR, Jose Sampaio. O entroncamento das políticas agrárias no Maranhão: encontros e desencontros institucionais na Microrregião Geográfica de Itapecuru Mirim. 311 f. Tese (Doutorado em Geografia) - Universidade Estadual Paulista, Faculdade de Ciências e Tecnologia. - Presidente Prudente, 2010.

MENDES, Diana. Nem Gaúcho, Nem Soja: mobilização camponesa para a criação da Resex Chapada Limpa. 112 f. Monografia (Graduação em Ciências Sociais). Universidade Federal do Maranhão. São Luís, 2015.

MORAES, Maria Dione. Um povo do cerrado entre baixões e chapadas - modo de vida e crise ecológica de camponeses (as) nos cerrados do sudoeste piauiense. In: GODÓI, E. P.; MENEZES, M. A.; MARIN, R. A. (Orgs.). Diversidade do campesinato: expressões e categorias. Vol. II. São Paulo: Editora da UNESP, 2009. p. 131-161.

MOTA, Francisco. O rural e o urbano na cidade de Balsas (MA): transformações socioespaciais no pós 1980. 139 f. Dissertação. (Mestrado em Geografia) - Programa de Pós-Graduação em Geografia. Universidade Federal de Uberlândia, 2011.

MUNIZ, Francisca. A vegetação da região de transição entre a Amazônia e o Nordeste, diversidade e estrutura. In: MOURA, E. G. (Org.). Agroambientes de transição: entre o trópico úmido e o semi-árido. São Luís: UEMA, 2002, p. 44-60.

NASCIMENTO, Silvane Magali. A reprodução do campesinato em Brejo (MA) e a participação das agricultoras familiares camponesas frente à expansão da monocultura de soja: duas lógicas de desenvolvimento. $330 \mathrm{f}$. Tese. (Doutorado em Políticas Públicas) - Programa de Pós Graduação em Políticas Públicas. Universidade Federal do Maranhão. São Luís, 2011.

OLIVEIRA, Danniel Maddson. "Admirável" Sertão Novo: o processo de territorialização da soja no município de Balsas, sul do Maranhão. 166 f. Monografia (Graduação em Geografia) - Departamento de Geociências. Universidade Federal do Maranhão. São Luís, 2011.

PALUDZYSZYN FILHO, Estefano. A cultura da soja no sul do Maranhão. Londrina: Empresa Brasileira de Pesquisa Agropecuária, 1995.

PAULA ANDRADE, Maristela de. A produção de carvão vegetal e o plantio de eucalipto no Leste Maranhense. In: CONCEIÇÃO, F. G. (Org.). Carajás: desenvolvimento ou destruição? Relatórios de Pesquisa. São Luís: CPT, 1995. p. 15-64.

PAULA ANDRADE, Maristela de. Os gaúchos descobrem o Brasil: projetos agropecuários contra a agricultura camponesa. São Luís: EDUFMA, 2008.

PAULA ANDRADE, Maristela de. (et al). Conflitos socioambientais no Leste Maranhense - problemas provocados pela atuação da Suzano Papel e Celulose e dos chamados gaúchos no Baixo Parnaíba. Relatório de Pesquisa. GERUR/PPGSoc/UFMA, 2012. 
SANTOS, Boaventura; MENESES, M. P. G; NUNES, J. A.Introdução: para ampliar o cânone da ciência: a diversidade epistemológica do mundo. In: Santos, B. S. (Org.). Semear outras soluções: os caminhos da biodiversidade e dos conhecimentos rivais. Rio de Janeiro: Civilização Brasileira, 2005. p. 19-101.

SCOTT, James. Formas cotidianas de resistência camponesa. Tradução de Marilda A. de Menezes e Lemuel Guerra. Revista Raízes, Campina Grande - PB, vol. 21, no 01, jan./jun. 2002, p. 10-31.

SHIRAISHI NETO, Joaquim. Grilagem de terras no Leste Maranhense. In: CONCEIÇÃO, F. G. (Org.). Carajás: desenvolvimento ou destruição? Relatórios de Pesquisa. São Luís: CPT, 1995. p. 67-80.

SILVA JÚNIOR, Amâncio. O castigo do sol além da praga da soja: repercussões do cultivo da soja sobre o modo de vida dos camponeses do povoado de Valença - Buriti (MA). 89 f. Monografia (Graduação em Ciências Sociais) - Curso de Ciências Sociais. Universidade Federal do Maranhão. São Luís, 2011.

SOUZA FILHO, Benedito. A produção de soja no sul do Maranhão e seus impactos para segmentos camponeses. In: CONCEIÇÃO, F. G. (Org.). Carajás: desenvolvimento ou destruição? Relatórios de Pesquisa. São Luís: CPT, 1995. p. 243-274.

SOUZA FILHO, Benedito. Os Pretos de Bom Sucesso: terra de preto, terra de santo, terra comum. - São Luís: EDUFMA, 2008.

SOUZA FILHO, Benedito. Conflitos e Estratégias para a Governança Territorial: o caso da Resex Chapada Limpa. Revista Pós Ciências Sociais, São Luís, v.11, n. 22. jul./dez. 2014, p. 43-60.

VELHO, Otávio. Frentes de expansão e estrutura agrária: estudo do processo de penetração numa área da Transamazônica - 3a ed. - Manaus: UEA Edições, 2013.

VIEIRA, Anderson. Entre a soja e a chapada: os agricultores familiares-artesãos de São João dos Pilões e a preservação da chapada frente ao avanço da lavoura da soja. 65 f. Monografia (Graduação em Ciências Sociais). Universidade Federal do Maranhão. São Luís, 2009. 